\title{
Experiência no Uso de Ferramentas Online Gamificadas na Introdução à Programação de Computadores
}

\author{
Claudia Akemi Izeki, Walter Aoiama Nagai, Rodrigo Moreira Carvalho Dias
}

\author{
Campus Itabira - Universidade Federal de Itajubá (UNIFEI) \\ Rua Irmã I. Drumond, 200 - Distrito Industrial II - 35.903-087 - Itabira - MG - Brazil \\ \{claudiaizeki, walternagai,rmcdias\}@unifei.edu.br
}

\begin{abstract}
Most students do not have basic knowledge of programming when they enter university. Consequently, they face difficulties as they lack problemsolving skills that are necessary in the field. The purpose of this article is to present the experience of using online gamification tools in the discipline 'Introduction to Programming', both to motivate students and to evaluate the reading of computer codes and strengthen the basics of the language with fast feedback. Additionally, general and gamified characteristics of these tools are presented.
\end{abstract}

Resumo. A maioria dos alunos que ingressam no ensino superior não possuem o conhecimento básico de programação e acabam tendo muitas dificuldades pela falta de habilidades necessárias, como a resolução de problemas. $O$ objetivo deste artigo é apresentar a experiência no uso de ferramentas online gamificadas na disciplina de Introdução à Programação, tanto para motivar os alunos quanto para avaliar a leitura de códigos de computador e reforçar os conceitos básicos da linguagem, com feedback rápido. Além disso, são apresentadas as características gerais e de gamificação dessas ferramentas.

\section{Introdução}

A Programação de Computadores é uma disciplina na qual os alunos que ingressam no ensino superior geralmente têm contato pela primeira vez, diferente de outras matérias como química, física ou matemática. Muitos não possuem o conhecimento do que é programar e, como é uma habilidade que usa muito o raciocínio lógico, a matemática e a capacidade de resolução de problemas, acabam tendo muita dificuldade, resultando em um alto índice de reprovações.

Como a programação é uma disciplina considerada difícil e desafiadora pelos alunos ingressantes, dois fatores são fundamentais para que se envolvam com a disciplina: motivação para estudar e feedback das atividades realizadas.

Alunos que ingressam em cursos como Ciência da Computação e Engenharia de Computação geralmente são mais motivados a resolverem problemas com a programação de computadores. O feedback é algo muito importante para saberem como estão em relação à turma e aos objetivos de aprendizagem da disciplina.

Uma forma de motivar os alunos a se engajar em uma disciplina é utilizar ferramentas baseadas em jogos (ou gamificadas). Segundo Rivera e Suescún (2015), a 
V Congresso Brasileiro de Informática na Educação (CBIE 2016)

Anais do XXII Workshop de Informática na Escola (WIE 2016)

avaliação baseada em jogo possibilita transformar uma avaliação "estressante e chata" em algo que avalie o conhecimento podendo, também, ser agradável; a avaliação com jogos é uma opção estratégica, pois os estudantes possuem uma atração inerente a jogos, são parte de suas vidas e "ganhar o jogo" é uma das recompensas mais valiosas.

A base para que o aluno consiga programar é entender os conceitos básicos da linguagem de programação, juntamente com a capacidade de ler e entender códigos de computador. Segundo Lister et al (2003), a capacidade de leitura de códigos é precursora para a resolução de problemas.

Neste trabalho foram empregadas três ferramentas online gamificadas na disciplina de Introdução à Programação de Computadores. O intuito era motivar os alunos e verificar seu entendimento no funcionamento básico da linguagem de programação e sua capacidade de leitura de código, além de feedback rápido.

Este artigo está organizado da seguinte forma: na Seção 2 são apresentadas as ferramentas online gamificadas utilizadas neste trabalho, com tabelas das características gerais e de gamificação; na Seção 3 é apresentada a aplicação dessas ferramentas na disciplina; na Seção 4 são apresentados resultados quantitativos e qualitativos a partir de questionários aplicados sobre suas experiências no uso dessas ferramentas na motivação e melhoria de aprendizagem. Finalmente, na Seção 5 são apresentadas as considerações finais deste trabalho.

\section{As Ferramentas Online Gamificadas}

O termo Gamification ou Gamificação possui vários significados e, segundo Kapp (2012), é a utilização de elementos de jogos como mecânica, estratégias e pensamentos com a finalidade de motivar indivíduos à ação, auxiliando na solução de problemas e promovendo a aprendizagem.

Na visão de Fardo (2013), a Gamificação proporciona um sistema em que os estudantes conseguem visualizar o efeito de suas ações e aprendizagens, na medida em que fica mais fácil compreender a relação das partes com o todo, como acontece nos jogos. Da mesma forma, um dos objetivos principais de introduzir uma experiência assim é para que os indivíduos sintam que seus objetivos contribuem para algo maior e mais importante, que suas ações fazem sentido dentro de uma causa maior.

No trabalho de Hunicke, Leblanc e Zubek (2004) é descrito o trabalho de um framework denominado MDA (Mechanics-Dynamics-Aesthetics) ou MDE (MecânicaDinâmica-Estética) que, basicamente, é a compilação de diversas pesquisas e contribuição de projetistas de desenvolvimento de jogos digitais. Na Figura 1, pode-se observar a interação das etapas do framework MDE.

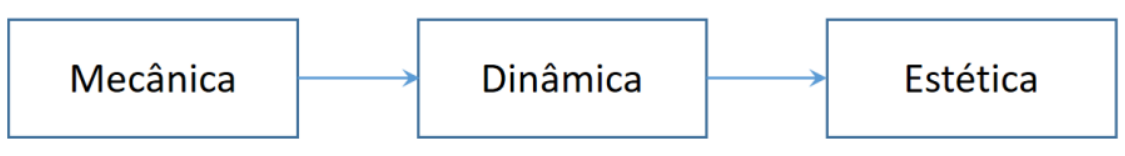

Figura 1. Esquema de Interação do Framework MDE, extraído de Hunicke, Leblanc e Zubek (2004), com tradução para o português. 
V Congresso Brasileiro de Informática na Educação (CBIE 2016)

Anais do XXII Workshop de Informática na Escola (WIE 2016)

A mecânica diz respeito a regras e componentes particulares de um jogo digital que representam dados e algoritmos, como pontos, placares, armas, etc. A dinâmica descreve o comportamento em tempo de execução que a mecânica atua nos jogadores durante o jogo, ou seja, o sistema do jogo. A estética descreve as respostas emocionais perceptíveis que o jogador possui durante a interação com o jogo que se traduz em diversão.

Neste trabalho foram empregadas três ferramentas online com características de gamificação: o curso de 20 horas da code.org (code.org, 2016), o Kahoot (Kahoot, 2016) e o Socrative (Socrative, 2016). Na Tabela 1 são apresentadas as características gerais dessas ferramentas. Já na Tabela 2 são descritas as características de gamificação observadas segundo o trabalho de Hunicke, Leblanc e Zubek (2004).

O curso de 20 horas da code.org inclui conceitos de estruturas condicionais, estruturas de repetição e funções em forma de jogos, com o estilo de programação de arrastar e soltar, além de feedback imediato e sugestões de melhoria no código. Nesse curso existem 9 etapas com uma média de 10 níveis cada. Em cada nível é apresentado um problema em que é necessário utilizar blocos específicos para sua resolução. Há alguns vídeos explicativos com personalidades internacionais no decorrer das etapas.

O objetivo do Kahoot, segundo seus criadores, é ser uma plataforma baseada em jogo que torna a aprendizagem divertida. O professor pode criar um questionário de múltipla escolha e estabelecer um tempo para a resposta de cada questão. $O$ aluno deverá responder cada questão antes que o tempo expire. Quanto mais rápido responder uma pergunta corretamente, melhor sua pontuação. É apresentado um ranking dos cinco melhores alunos a cada questão.

Já o Socrative é uma ferramenta que permite ao professor engajar e avaliar os alunos enquanto a aprendizagem ocorre. $\mathrm{O}$ professor pode criar um questionário e aplicá-lo de diferentes formas, de acordo com a metodologia de ensino empregada. $\mathrm{O}$ aluno deverá responder o questionário em um tempo total determinado pelo professor, que pode visualizar as respostas de cada aluno ao mesmo tempo em que eles respondem as perguntas. O Socrative suporta atividade colaborativa com a Corrida Espacial, em que grupos de alunos resolvem as questões em conjunto, projetando-se o progresso de cada grupo em tempo real, o que estimula a competição entre eles.

Tabela 1. Características gerais das ferramentas online utilizadas

\begin{tabular}{|l|c|c|c|}
\cline { 2 - 4 } \multicolumn{1}{c|}{} & CODE.ORG & KAHOOT & SOCRATIVE \\
\hline Dispositivo & $\begin{array}{c}\text { Qualquer um com acesso } \\
\text { a navegador e Internet. }\end{array}$ & $\begin{array}{c}\text { Qualquer um com acesso } \\
\text { a navegador e Internet. }\end{array}$ & $\begin{array}{c}\text { Qualquer um com acesso } \\
\text { a navegador e Internet. }\end{array}$ \\
\hline $\begin{array}{l}\text { Cadastro } \\
\text { professor }\end{array}$ & Sim & Sim & Sim \\
\hline Cadastro do aluno & Sim & Não & Pelo link \\
\hline $\begin{array}{l}\text { Forma de acesso } \\
\text { pelo aluno }\end{array}$ & $\begin{array}{l}\text { Após o professor criar uma } \\
\text { turma, é gerado um link. O } \\
\text { aluno deve acessá-lo para se } \\
\text { "matricular" no curso. }\end{array}$ & $\begin{array}{c}\text { Pelo link } \text { http://kahoot.it, } \\
\text { digitando o código do } \\
\text { questionário e depois seu } \\
\text { nickname. }\end{array}$ & $\begin{array}{c}\frac{\mathrm{http} / / \text { b.socrative.com/logi }}{\mathrm{n} / \text { student/, digitando o }} \\
\text { código da sala e depois } \\
\text { seu nickname. }\end{array}$ \\
\hline
\end{tabular}


V Congresso Brasileiro de Informática na Educação (CBIE 2016)

Anais do XXII Workshop de Informática na Escola (WIE 2016)

\begin{tabular}{|c|c|c|c|}
\hline $\begin{array}{l}\text { Permite criação de } \\
\text { problemas }\end{array}$ & Não & Sim & Sim \\
\hline $\begin{array}{l}\text { Tipos de } \\
\text { questões/problemas }\end{array}$ & $\begin{array}{l}\text { Os problemas são fixos, } \\
\text { pré-determinados. }\end{array}$ & $\begin{array}{l}\text { Apenas de múltipla } \\
\text { escolha, com a opção de } \\
\text { mais de uma resposta } \\
\text { correta. }\end{array}$ & $\begin{array}{l}\text { Múltipla escolha, } \\
\text { verdadeiro/falso e } \\
\text { resposta curta. }\end{array}$ \\
\hline $\begin{array}{lr}\text { Mídias } & \text { para } \\
\text { apresentação } & \text { do } \\
\text { problema/questão }\end{array}$ & Texto, Imagem e Vídeo. & Texto, Imagem e Vídeo. & Texto e Imagem. \\
\hline $\begin{array}{lr}\text { Mídias } & \text { para } \\
\text { apresentação } & \text { das } \\
\text { alternativas } & \text { de } \\
\text { resposta } & \\
\end{array}$ & N/A & Apenas texto. & Apenas texto. \\
\hline $\begin{array}{l}\text { Formatação do } \\
\text { texto da questão e } \\
\text { das alternativas de } \\
\text { respostas }\end{array}$ & N/A & $\begin{array}{c}\text { Sim, mas poucas opções } \\
\text { como negrito, itálico e } \\
\text { sublinhado. }\end{array}$ & $\begin{array}{l}\text { Sim, mas poucas } \\
\text { opções como negrito, } \\
\text { itálico e sublinhado. }\end{array}$ \\
\hline $\begin{array}{l}\text { Quantidade máxima } \\
\text { de caracteres no } \\
\text { enunciado e nas } \\
\text { alternativas }\end{array}$ & N/A & $\begin{array}{c}95 \text { caracteres para o } \\
\text { enunciado e } 60 \\
\text { caracteres para cada } \\
\text { alternativa de resposta. }\end{array}$ & Não há. \\
\hline $\begin{array}{ll}\text { Visualização } & \text { do } \\
\text { enunciado } & \text { do } \\
\text { problema } & \\
\end{array}$ & $\begin{array}{l}\text { No próprio dispositivo } \\
\text { utilizado pelo aluno. }\end{array}$ & $\begin{array}{c}\text { Projetado em um local } \\
\text { compartilhado, como em } \\
\text { uma parede. }\end{array}$ & $\begin{array}{l}\text { No próprio dispositivo } \\
\text { utilizado pelo aluno. }\end{array}$ \\
\hline $\begin{array}{l}\text { Visualização das } \\
\text { opções de resposta }\end{array}$ & $\begin{array}{l}\text { Não possui. O aluno } \\
\text { deve criar sua resposta, } \\
\text { geralmente do zero. }\end{array}$ & $\begin{array}{c}\text { Projetado em um local } \\
\text { compartilhado, como em } \\
\text { uma parede. }\end{array}$ & $\begin{array}{l}\text { No próprio dispositivo } \\
\text { utilizado pelo aluno. }\end{array}$ \\
\hline $\begin{array}{l}\text { Opções de aplicação } \\
\text { de questionário }\end{array}$ & N/A & Apenas uma. & $\begin{array}{l}\text { Três tipos: (i) no ritmo } \\
\text { do estudante - } \\
\text { feedback imediato, (ii) } \\
\text { no ritmo do estudante - } \\
\text { navegação do } \\
\text { estudante, e (iii) no } \\
\text { ritmo do professor. }\end{array}$ \\
\hline $\begin{array}{l}\text { Possibilidade de o } \\
\text { aluno mudar sua } \\
\text { resposta }\end{array}$ & $\begin{array}{l}\text { Sim, a qualquer } \\
\text { momento. }\end{array}$ & Não & $\begin{array}{c}\text { Sim, dependendo da } \\
\text { opção de aplicação de } \\
\text { questionário. }\end{array}$ \\
\hline $\begin{array}{lr}\text { Facilidade } & \text { na } \\
\text { elaboração } & \text { dos } \\
\text { problemas } & \\
\end{array}$ & N/A & $\begin{array}{c}\text { Sim. Interface intuitiva e } \\
\text { simples. }\end{array}$ & $\begin{array}{l}\text { Sim. Interface intuitiva } \\
\text { e simples. }\end{array}$ \\
\hline $\begin{array}{l}\text { Geração } r \text { de } \\
\text { relatórios (para } 0 \\
\text { professor) } \\
\text { rendimento de cada } \\
\text { aluno e da turma }\end{array}$ & Sim & Sim & Sim \\
\hline $\begin{array}{l}\text { Atividade } \\
\text { Colaborativa }\end{array}$ & $\begin{array}{c}\text { Sim, com a Programação } \\
\text { em Pares. }\end{array}$ & Sim, no modo Team. & $\begin{array}{l}\text { Sim, com a Corrida } \\
\text { Espacial. }\end{array}$ \\
\hline
\end{tabular}


V Congresso Brasileiro de Informática na Educação (CBIE 2016)

Anais do XXII Workshop de Informática na Escola (WIE 2016)

Tabela 2. Características de gamificação observadas nas ferramentas online

\begin{tabular}{|c|c|c|c|}
\hline & CODE.ORG & КАHOOT & SOCRATIVE \\
\hline Mecânica & $\begin{array}{l}\text { Progresso, quantidade de } \\
\text { linhas de código escritas, } \\
\text { se o código foi realizado } \\
\text { com o menor número de } \\
\text { instruções, sugestões de } \\
\text { melhoria no código, } \\
\text { quantidade de problemas } \\
\text { resolvidos, troféus e } \\
\text { certificado. }\end{array}$ & $\begin{array}{l}\text { Progresso, contagem } \\
\text { regressiva do tempo de } \\
\text { respostas, feedback das } \\
\text { respostas, gráfico com a } \\
\text { quantidade de alunos para } \\
\text { cada resposta em tempo } \\
\text { real, placar e ranking dos } 5 \\
\text { melhores alunos. }\end{array}$ & $\begin{array}{l}\text { Progresso, pontuação, } \\
\text { ranking (apenas no modo } \\
\text { Corrida Espacial), além de } \\
\text { feedback e explicação das } \\
\text { respostas. }\end{array}$ \\
\hline Dinâmica & $\begin{array}{l}\text { Resolver cada problema } \\
\text { com a quantidade de } \\
\text { blocos recomendada, } \\
\text { aumentando o nível de } \\
\text { dificuldade a cada } \\
\text { problema e etapa. Auxílio } \\
\text { de vídeos. }\end{array}$ & $\begin{array}{c}\text { Responder corretamente } \\
\text { cada questão o mais rápido } \\
\text { possível. O tempo expira a } \\
\text { cada questão. }\end{array}$ & $\begin{array}{l}\text { Responder corretamente } \\
\text { cada questão. Há um tempo } \\
\text { total determinado pelo } \\
\text { professor (quando o } \\
\text { professor clica em } \\
\text { "Finalizar", acaba-se o } \\
\text { tempo). }\end{array}$ \\
\hline Estética & $\begin{array}{c}\text { Fantasia, Desafio e } \\
\text { Descoberta. }\end{array}$ & $\begin{array}{c}\text { Colaboração (no Kahoot } \\
\text { em Grupo), Desafio e } \\
\text { Descoberta. }\end{array}$ & $\begin{array}{l}\text { Colaboração (no modo } \\
\text { Corrida Espacial), Fantasia } \\
\text { (no modo Corrida } \\
\text { Espacial), Desafio e } \\
\text { Descoberta. }\end{array}$ \\
\hline
\end{tabular}

\section{Aplicação das Ferramentas}

Como a programação de computadores é uma disciplina que geralmente os alunos não têm contato antes de ingressar no ensino superior, sua aprendizagem torna-se mais complicada para a maioria deles.

Assim, o objetivo em utilizar o curso de 20 horas da code.org foi de o aluno conhecer os conceitos básicos da programação de uma forma descontraída e divertida para depois relacionar esses conceitos com os vistos em sala de aula, resultando em uma aprendizagem significativa. Segundo Novak \& Cañas (2009), a aprendizagem significativa propõe que a tarefa de aprendizagem deve relacionar uma nova informação a outros conceitos relevantes já existentes na estrutura cognitiva, que é o conhecimento existente de um indivíduo.

O objetivo em utilizar a ferramenta Kahoot foi de reforçar e fixar os conceitos básicos da linguagem de programação, testando se realmente a ferramenta estimula a aprendizagem dos alunos de forma divertida. Já o objetivo em utilizar o Socrative também foi de reforçar conceitos básicos, verificando se os alunos haviam realizado um estudo dirigido prévio.

É importante ressaltar que o professor deve conhecer as características de gamificação que cada ferramenta possui, principalmente a dinâmica, para verificar em que momento da aprendizagem - e como - ele deverá aplicar a ferramenta. 
V Congresso Brasileiro de Informática na Educação (CBIE 2016)

Anais do XXII Workshop de Informática na Escola (WIE 2016)

No primeiro semestre de 2016 foram utilizadas pela primeira vez as ferramentas Kahoot e Socrative em algumas turmas de Engenharia na instituição dos autores: de Computação, de Controle e Automação, de Elétrica e de dependentes. O curso de 20 horas da code.org já vinha sido aplicado desde 2014 na instituição para turmas de Engenharia de Computação. A maioria das atividades foram realizadas em laboratórios de informática com acesso a computadores e Internet.

As atividades na code.org e no Socrative contribuíram na nota da disciplina de programação básica, sendo que as atividades no Kahoot não, pois existe a pressão em responder cada questão em alguns segundos.

É importante destacar que o professor aproveitava o feedback das ferramentas Socrative e Kahoot para intervir na explicação das questões com maior número de erros, o que resultava em momentos muito ricos de aprendizagem.

\subsection{Curso de 20 horas da code.org}

Nesse curso são abordados conceitos básicos de programação como estruturas condicionais, repetição e funções. Foram 9 etapas, com aproximadamente 10 níveis cada, para serem finalizadas em 40 dias após o início das aulas do primeiro semestre de 2016. A primeira etapa, geralmente utilizada no evento "A Hora do Código" (https://hourofcode.com), foi realizada no primeiro dia de laboratório com o objetivo de motivar os alunos, sendo que as demais foram realizadas fora do horário de aula.

Um total de 64 alunos realizaram o curso de 20 horas da code.org. Na Tabela 3 é apresentada a porcentagem dos níveis completados em cada etapa. Observa-se uma queda nessa porcentagem no decorrer das etapas, onde aumentou a quantidade de alunos que deixou a etapa em branco. Algumas razões para isso são apresentadas na Seção 4.

Tabela 3. Porcentagem de níveis completados e de alunos que deixaram a etapa em branco no curso de $\mathbf{2 0}$ horas da code.org

\begin{tabular}{|c|c|c|c|c|c|c|c|c|c|}
\cline { 2 - 11 } \multicolumn{1}{c|}{} & \multicolumn{10}{c|}{ ETAPA } \\
\cline { 2 - 12 } & $\mathbf{1}$ & $\mathbf{2}$ & $\mathbf{3}$ & $\mathbf{4}$ & $\mathbf{5}$ & $\mathbf{6}$ & $\mathbf{7}$ & $\mathbf{8}$ & $\mathbf{9}$ \\
\hline \% níveis completados & 93,7 & 88,3 & 89,1 & 85,1 & 82,1 & 73,0 & 63,4 & 67,2 & 73,4 \\
\hline \% alunos que não realizaram a etapa & 0 & 2 & 10 & 11 & 14 & 21 & 23 & 28 & 26 \\
\hline
\end{tabular}

\subsection{Kahoot}

Foram elaborados dois questionários no Kahoot para avaliar conceitos básicos, como operadores (lógicos, aritméticos, relacionais e de atribuição) e estruturas condicionais. Prezou-se por questões com conceitos que iniciantes de programação mais têm dificuldades na linguagem utilizada na disciplina $(\mathrm{C}++)$, como confundir o operador de comparação de igualdade com o operador de atribuição, uso de operadores lógicos, precedência de operadores, operador de resto de divisão, divisão entre operandos inteiros e análise de código com estruturas condicionais simples e compostas. Ambos os questionários possuíam, em média, 10 questões. 
V Congresso Brasileiro de Informática na Educação (CBIE 2016)

Anais do XXII Workshop de Informática na Escola (WIE 2016)

As etapas de elaboração das questões, tanto no Kahoot quanto no Socrative, até sua aplicação podem ser vistas na Figura 2. É muito importante, antes da aplicação do questionário, fazer testes e realizar possíveis alterações.

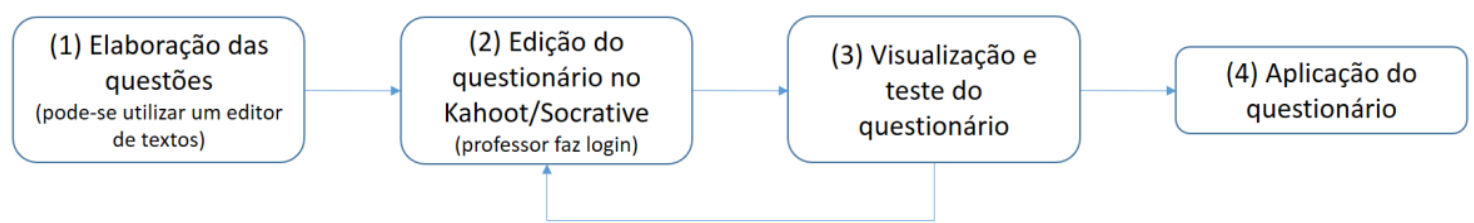

Figura 2. Etapas de elaboração de um questionário no Kahoot e no Socrative até sua aplicação

É imprescindível destacar que na fase de elaboração das questões deve-se ter em mente as características gerais do Kahoot já apresentadas anteriormente (Tabela 1) como, por exemplo: cada questão deve ser do tipo múltipla escolha; o texto do enunciado e das alternativas devem ser sucintas; a configuração de tempo de resposta deve estar condizente com o nível da questão, podendo-se utilizar a Taxonomia de Bloom (Ferraz e Belhot, 2010) para isso, quanto maior o nível maior o tempo; caso haja algum trecho de código como imagem, verificar se ficará legível ao projetá-lo na tela; dentre outras.

Responderam ao primeiro e segundo questionários, 61 e 55 alunos, respectivamente. A maioria dos alunos usou smartphones, outros usaram os computadores do laboratório de informática. Ao analisar a porcentagem de acertos em cada questão, verificou-se que questões com um nível de Bloom maior e que possuíam alguma imagem para analisar, foram as mais difíceis e, portanto, a porcentagem de alunos que acertou foi menor. A porcentagem de acertos em cada questão, no primeiro questionário, variou de $39 \%$ a $82 \%$. No questionário 2 variou de $25 \%$ a $95 \%$. Ao analisar melhor os dados gerados pelo Kahoot, percebeu-se que algumas questões possuíam uma porcentagem de acertos baixa porque vários alunos não responderam à questão, o que pode indicar que seria necessário aumentar o tempo de resposta. Durante a aplicação do questionário foram observados, pelo professor, comportamentos como empolgação, competição, atenção e frustração.

\subsection{Socrative}

Foram elaborados e aplicados dois questionários no Socrative: um sobre conceitos básicos de vetores e outro focado no primeiro projeto da disciplina com conceitos como caracteres, strings, matriz de caracteres e vetores, ambos com 11 questões cada.

$\mathrm{Na}$ fase de elaboração do questionário, deve-se ter em mente as características gerais da ferramenta (Tabela 1), tais como: cada questão pode ser do tipo verdadeiro/falso, múltipla escolha ou resposta curta; pode-se usar imagem e texto no enunciado da questão, mas apenas texto como alternativas de respostas; pode-se formatar os textos de forma simples, dentre outras.

Cada questionário foi aplicado em duas fases: primeiro de forma individual sem feedback; e depois em dupla (modalidade Corrida Espacial), com feedback e pontuação a cada questão. No primeiro questionário, na fase individual, participaram 47 alunos e a porcentagem de acertos em cada questão variou de $6 \%$ a $91 \%$; na fase em dupla a 
V Congresso Brasileiro de Informática na Educação (CBIE 2016)

Anais do XXII Workshop de Informática na Escola (WIE 2016)

porcentagem de acertos variou de $43 \%$ a $100 \%$. No segundo questionário, na fase individual, participaram 50 alunos e a porcentagem de acertos variou de $14 \%$ a $76 \%$; na fase em dupla a porcentagem variou de $33 \%$ a $100 \%$. Percebeu-se que na Corrida Espacial houve um aumento significativo no rendimento dos alunos, na qual foram observadas muitas interações entre os alunos, mesmo entre as duplas com rendimentos discrepantes entre os alunos. Todos os alunos usaram os computadores do laboratório para a realização dos questionários.

\section{Resultados das experiências dos alunos nas ferramentas}

Foram aplicados três questionários sobre a experiência dos alunos em cada ferramenta. Nem todos os alunos que participaram das atividades responderam a esses questionários, mas a porcentagem dos que experimentaram e responderam aos questionários do curso de 20 horas da code.org, do Kahoot e do Socrative foram, respectivamente, 75\%, 80\% e $100 \%$. As perguntas mais significativas de cada questionário, com suas respectivas respostas, estão listadas nas Tabelas 4,5 e 6 .

Tabela 4. Questionário de experiência na atividade do curso da code.org

(1) Você chegou a completar o curso de 20 horas da code.org, recebendo um certificado ao final do curso? Resultado: $79,2 \%$ responderam sim.

(2) Se não completou, qual foi o motivo? Resultado: $70 \%$ por esquecimento, $10 \%$ por achar muito difícil e $20 \%$ pela falta de tempo.

(3) Como foi sua experiência no uso da code.org? Você se sentiu bem ao realizar as atividades propostas? Resultado: $81,2 \%$ responderam que se sentiram bem; os demais responderam que era cansativo e repetitivo.

(4) O objetivo principal da code.org é promover uma introdução divertida à programação. Você concorda com essa afirmação? Resultado: $97,9 \%$ responderam que sim. $\mathrm{O}$ aluno que respondeu não disse que achou muito infantil a maneira apresentada.

(5) O curso de 20 horas da code.org (com os problemas, os temas, os troféus, os blocos de programação, os vídeos) o motivava a fazê-lo, a passar as fases? Resultado: $89,6 \%$ responderam afirmativamente. Os demais responderam que a atividade era maçante e que não gostavam da programação por blocos.

(6) Quando você resolvia os problemas da code.org você se sentia como se estivesse em um jogo? Resultado: 94,6\% responderam afirmativamente.

(7) $\mathrm{O}$ curso o ajudou a entender os conceitos básicos de programação, como condicionais, repetição e funções? Resultado: $97,9 \%$ disseram sim.

(8) Qual foi o tópico que mais teve dificuldade? Resultado: 68,8\% responderam Funções, 25\% responderam Estruturas de Repetição e 6,3\% responderam Estruturas Condicionais.

(9) Você teria realizado o curso de 20 horas da code.org caso não valesse ponto? Resultado: $74,4 \%$ responderam sim.

Tabela 5. Questionário de experiência na atividade com o Kahoot

(1) A definição do Kahoot é: "Uma plataforma de aprendizagem baseada em jogo que é divertido aprender". Você concorda com essa frase? Como foi sua experiência no uso do kahoot? Você se sentiu bem ao usá-lo? Resultado: $88,2 \%$ responderam afirmativamente. Utilizaram termos como "forma diferente de ensino", competição, motivação, empolgação, descontração, interessante, boa experiência, 
V Congresso Brasileiro de Informática na Educação (CBIE 2016)

Anais do XXII Workshop de Informática na Escola (WIE 2016)

dinâmico, aprendizado e brincadeira.

(2) Você se divertia respondendo as questões? Resultado: $90 \%$ concordaram.

(3) Você se sentiu inserido em um jogo? Resultado: $87,8 \%$ concordaram.

(4) Você gostaria de realizar mais atividades no kahoot? Resultado: $95,9 \%$ concordaram.

(5) Ao saber que em uma aula você fará atividades no Kahoot, SEM VALER PONTO, você estudaria mais o conteúdo da disciplina? Resultado: $81,8 \%$ concordaram e a maioria deles afirmou que a motivação era a competição.

(6) Você acha que o Kahoot estimula a aprendizagem de conteúdos da disciplina? Resultado: 98\% concordaram

Tabela 6. Questionário de experiência na atividade do Socrative

(1) Como foi sua experiência na atividade INDIVIDUAL no uso do Socrative? Você se sentiu bem ao usá-lo? Resultado: $84 \%$ responderam que sentiram bem ao usá-lo. Os alunos usaram os termos/frases: forma dinâmica e divertida, boa experiência, cria ambiente competitivo, interessante, forma diferente e agradável, incentivo a mais para estudar, interface muito boa.

(2) Como foi sua experiência na atividade em DUPLA no uso do Socrative? Você se sentiu bem ao usálo? Resultado: $98 \%$ responderam que foi boa, utilizando termos/frases como "bastante produtiva", "experiência muito boa", "Um pouco melhor, por serem duas pessoas a dividir experiência", "melhor que a atividade individual", "esclarecimento de dúvidas com o companheiro", "Excelente, quando somam-se conhecimentos o resultado é muito positivo", "o desempenho foi superior". O único aluno que respondeu NÃO disse que o parceiro não havia estudado, então não agregou em nada.

(3) O quanto você acha que aprendeu com a atividade em DUPLA no Socrative? Resultado: $72 \%$ responderam Muito; $2 \%$ responderam nada e $25 \%$ mais ou menos.

(4) Pela atividade em dupla ter o ambiente de uma corrida espacial isso o motivou a responder às questões? Resultado: $68,6 \%$ responderam sim.

(5) Ao realizar a atividade INDIVIDUAL você se sentia como se estivesse em um jogo? Resultado: $72,5 \%$ responderam sim.

(6) Ao realizar a atividade DUPLA você se sentia como se estivesse em um jogo? Resultado: $80,4 \%$ responderam que sim.

(7) Você acha que o Socrative estimula a aprendizagem? Resultado: 100\% responderam sim.

(8) Você gostaria de realizar mais atividades no Socrative? Resultado: 92,2\% responderam sim.

\section{Considerações Finais}

A gamificação é uma estratégia de ensino que vem sendo muito utilizada para proporcionar engajamento dos alunos nas atividades propostas pelo professor, aproveitando-se do fato que os alunos possuem uma atração inerente a jogos.

O objetivo deste trabalho foi de aplicar algumas ferramentas online com características de gamificação na disciplina de Introdução à Programação de Computadores. O intuito era (i) motivar os alunos a estudarem e (ii) verificar seu entendimento no funcionamento básico da linguagem de programação e em sua capacidade de leitura de código, com (iii) feedback rápido. Neste trabalho, cada uma das ferramentas teve sua contribuição, mas todas motivam no estudo da programação de computadores: o curso da code.org para que os alunos tenham conhecimento básico de 
V Congresso Brasileiro de Informática na Educação (CBIE 2016)

Anais do XXII Workshop de Informática na Escola (WIE 2016)

programação, o Kahoot para perguntas rápidas com conceitos básicos de programação e o Socrative para os conceitos básicos e avaliação da capacidade de leitura de códigos.

Ao pretender utilizar uma ferramenta com características de gamificação, o professor deve conhecer as características de gamificação que cada ferramenta possui, principalmente a dinâmica, para verificar em que momento da aprendizagem - e como ele deverá aplicar a ferramenta. Além disso, o professor deve conhecer as características gerais de ferramentas como o Kahoot e o Socrative para planejar cada questão.

Ao analisar os dados dos questionários, a maioria dos alunos se sentiu bem ao usar as três ferramentas, inserindo-se em um jogo; as ferramentas auxiliaram na aprendizagem dos conceitos e, o mais importante, os alunos gostariam de realizar mais atividades nessas ferramentas. O feedback que as ferramentas proporcionam é útil tanto para os alunos quanto para o professor, que possui certo trabalho na elaboração do questionário, mas uma vez criado e aplicado, as ferramentas geram automaticamente relatórios de desempenho da turma e de cada aluno. Assim, o professor pode intervir (durante ou logo após a atividade) nos conceitos mais complicados para os alunos.

\section{Agradecimento}

Agradecemos à Fundação de Pesquisa de Minas Gerais (FAPEMIG) pelo apoio financeiro.

\section{Referências}

Code.org. Curso de Introdução Acelerada ao CS. Disponível em: $<$ https://studio.code.org/s/20-hour $>$. Acesso em: 30/05/2016.

Fardo, M. L. A Gamificação Aplicada em Ambientes de Aprendizagem. RENOTE. Revista Novas Tecnologias na Educação, v. 11, p. 1, 2013.

Ferraz, Ana Paula do Carmo Marcheti; Belhot, Renato Vairo. Taxonomia de Bloom: revisão teórica e apresentação das adequações do instrumento para definição de objetivos instrucionais. Gest. Prod., São Carlos, v. 17, n. 2, p.421-431, jan. 2010.

Hunicke, R.; Leblanc, M.; Zubek, R. MDA: a Formal Approach to Game Design and Game Research. In Proceedings of the Challenges in Games AI Workshop, Nineteenth National Conference of Artificial Intelligence. Press. p. 1-5, 2004.

Kahoot. Make Learning Awesome. Disponível em: <https://getkahoot.com/>. Acesso em: 30/06/2016.

Kapp, K. The Gamification of Learning and Instruction: Game-based Methods and Strategies for Training and Education. Pfeiffer, 2012.

Lister, Raymond et al. A Multi-National Study of Reading and Tracing Skills in Novice Programmers, SIGCSE Bulletin, v.36, n. 4, p. 119-150, 2004.

Novak, J. D. \& Cañas, A. J. How People Learn. 2009. Disponível em: $<$ http://cmap.ihmc.us/docs/howpeoplelearn.html >. Acessado em 30/05/2016.

Rivera, L. F. Z. and Suescún, C. A. Game-Based Assessment for Radiofrequency Circuits courses in Engineering, In: Frontiers in Education Conference (FIE), El Paso, TX, IEEE, 2015.

Socrative. Visualizing Student Understanding has Never been Clear. Disponível em: $<$ http://www.socrative.com/>. Acesso em: 30/05/2016. 